11

\title{
О возможности регистрации спектров ядерного магнитного резонанса жидких сред в слабых полях в экспресс-режиме
}

\author{
() В.В. Давыдов, ${ }^{1}$ Н.С. Мязин, ${ }^{1}$ В.И. Дудкин, ${ }^{2}$ Н.М. Гребеникова ${ }^{1}$ \\ ${ }^{1}$ Санкт-Петербургский политехнический университет Петра Великого, \\ 195251 Санкт-Петербург, Россия \\ ${ }^{2}$ Санкт-Петербургский государственный университет телекоммуникаций им. проф. М.А. Бонч-Бруевича, \\ 193232 Санкт-Петербург, Россия \\ e-mail: davydov_vadim66@mail.ru
}

(Поступило в Редакцию 15 января 2018 г. В окончательной редакции 8 мая 2018 г.)

Обоснована необходимость регистрации спектров ядерного магнитного резонанса (ЯМР) в слабых магнитных полях при экспресс-контроле жидких сред, и определены условия, при которых эта регистрация возможна. Для таких измерений предложена новая схема малогабаритного ЯМР-спектрометра. Представлены результаты экспериментальных исследований некоторых веществ, выполненные по разработанной методике.

DOI: $10.21883 /$ JTF.2018.12.46793.24-18

\section{Введение}

В настоящее время круг задач технической физики, для решения которых проводятся различные исследования, чрезвычайно широк [1-6]. Одной из них является создание быстрых и надежных методов экспресс-контроля состояния жидких сред в экспресс-режиме [7-11]. В большинстве случаев разработанные для ее решения приборы используются для измерений на ограниченном числе сред. Например, рентгенофлуоресцентный анализатор „S1 TITAN Bruker“ для неразрушающего химического анализа металлов и сплавов или ультразвуковые анализаторы качества молочных продуктов серии „Экомилк $\mathrm{M} “^{“}$. При использовании их для определения состояния других сред, например, биологических растворов, спирта или сока, выполненные с их помощью измерения вносят необратимые изменения в физическую структуру и химический состав исследуемой среды, а также могут изменять ее вкусовые качества. Совершенствование или использование новых методик в данных приборах для повышения точности измерений ничего не изменяет в этом направлении. Получить подтверждение выявленных отклонений в пробе среды после таких исследований на приборах более высокого разрешения в стационарных лабораториях (например, различных типы спектрометров) невозможно. Также возникают проблемы при использовании после таких исследований сред, находившихся в этих пробах, по их непосредственному назначению $[9,10,12-15]$. Поэтому при экспресс-контроле в последнее время предпочтение стали отдавать приборам, которые не вносят существенных изменений в исследуемую среду и могут применяться для контроля состояния большого числа различных сред. Например, оптические анализаторы: BALTECHOA-500 для контроля состояния различных типов масел, или измерители, работающие в ИК диапазоне, для определения содержания воды в нефти и нефтепродуктах [16], температуры [17] и т.д. К бесконтактным приборам относятся некоторые электромагнитные измерители, например, IT-1М для определения содержания воды в углеводородных соединениях или измеритель состояния трансформаторного масла для определения напряжения пробоя [18], а также все модели ядерно-магнитных измерителей $[2,3,5,6,10,13,14,19-22]$. В работах $[10,13,14]$ подробно рассмотрены преимущества и недостатки этих приборов, а также представлены результаты экспериментальных исследований. Анализ полученных результатов показал, что наиболее универсальными и многофункциональными являются приборы, принцип работы которых основан на явлении ядерного магнитного резонанса (ЯМР).

Исследования различных жидких сред в экспрессрежиме с использованием ранее разработанного нами малогабаритного ЯМР-релаксометра $[10,13,14]$ позволили установить один существенный недостаток методики определения состояния среды по измеренным значениям $T_{1}$ и $T_{2}$.

Экспериментально было установлено, что некоторые химические элементы (например, фтор, калий, магний, кальций и т.д.) даже при небольших их концентрациях в воде вызывают значительные отклонения времен релаксации от значений $T_{1}$ и $T_{2}$, соответствующих ее стандартному состоянию. С повышением температуры воды отмеченная разница между временами релаксации увеличивается. Многочисленные исследования различных ученых показали, что в небольших концентрациях в воде данные химические элементы не представляют опасность для живых организмов. Кроме того, необходимо отметить, что химические элементы (например, фтор, калий, магний и т.д.) довольно часто встречаются в водных средах, особенно в природных условиях при экологическом мониторинге. Установить их наличие в среде по измеренным методом ЯМР константам релаксации $T_{1}$ и $T_{2}$ невозможно.

По этой причине может быть допущена ошибка в определении состояния среды (например, она представляет опасность для живых организмов), и сделано неверное заключении о возможности ее использования 
в настоящий момент. На основании этого заключения будет принято решение о проведении дополнительных исследований проб, содержащих эту среду, в стационарных лабораториях с использованием приборов высокого разрешения (ЯМР- или ЭПР-спектрометров) или химическим анализом. Это приведет к необязательным расходам материальных средств на проведение исследования и к потере времени на ожидание их результатов. Одна из основных задач экспресс-контроля не выполнена.

Кроме того, в настоящее время часто возникают ситуации, когда необходимо кроме контроля состояния самой жидкой среды в месте взятия пробы определить соотношение между образующими ее компонентами и незамедлительно принять меры по устранению выявленных отклонений.

Одним из возможных вариантов решения данной задачи является регистрация сигналов ЯМР в слабом магнитном поле на резонансных частотах (спектра) от химических элементов жидкой среды, обладающих магнитным моментом. В первую очередь от ядер фтора, магния, калия, натрия и т. д. Это позволит установить их наличие в исследуемой среде в месте взятия пробы (например, в полевых условия и т.д.), а по амплитуде регистрируемых сигналов ЯМР определить их относительные концентрации в среде. Полученные результаты значительно уменьшают вероятность ошибки при определении состояния среды и возможностей ее дальнейшего использования.

\section{Малогабаритный ядерно-магнитный спектрометр и методика регистрации спектра}

В соответствии с принятыми мировыми стандартами вес измерительного прибора для проведения исследования сред в экспресс-режиме должен быть менее $10 \mathrm{~kg}$. Основной вклад в массогабаритные характеристики ЯМР-спектрометров вносят магнитные системы

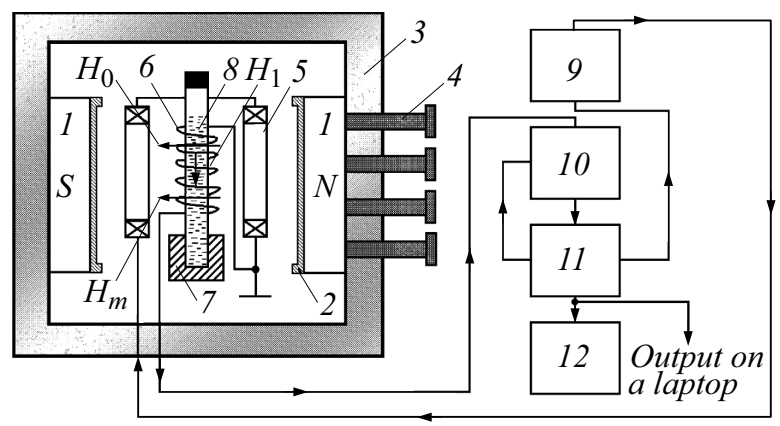

Рис. 1. Структурная схема малогабаритного ЯМР-спектрометра: 1 - постоянный магнит, 2 - вставки для полюсных наконечников, 3 - нейтраль для размещения и центровки магнитов, 4 - регулировочные винты, 5 - катушки модуляции, 6 - катушка регистрации сигнала ЯМР, 7 - фиксирующее устройство для контейнера с исследуемой средой, $8-$ контейнер с исследуемой средой, $9-$ радиочастотный генератор, 10 - автодинный детектор, 11 - устройство обработки и управления, 12 - осциллограф.

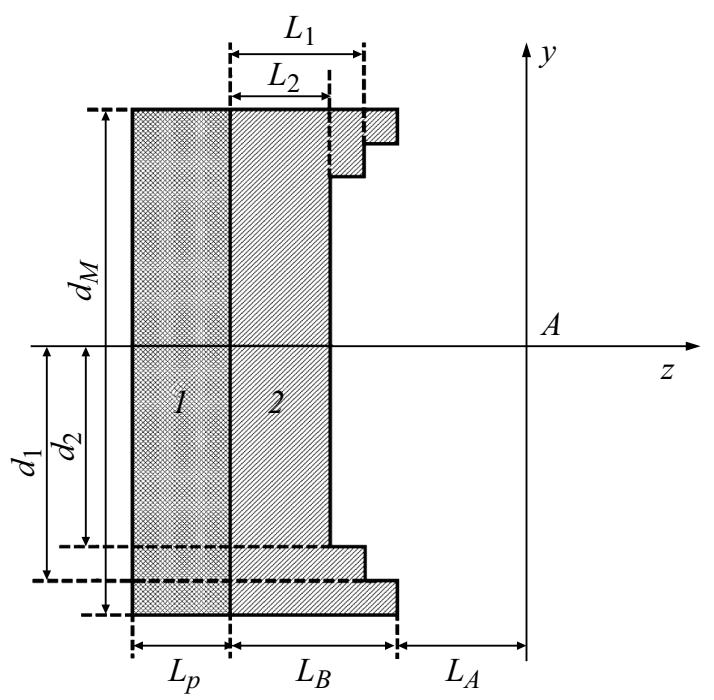

Рис. 2. Общий вид полюса магнита со вставкой: 1 - полюс магнита, 2 - вставка.

и обслуживающие их устройства [2,3,5,6,10,13,14,19-24]. В состав ранее разработанной конструкции малогабаритного ЯМР релаксометра $[10,13,14]$ кроме магнитной системы, устройств регистрации и обработки сигнала ЯМР также входил ноутбук и автономный источник питания с аккумуляторными батареями. Данные элементы также необходимы и в новой конструкции ЯМР-спектрометра. В сложившейся ситуации для обеспечения мобильности новой конструкции малогабаритного ЯМР-спектрометра для экспресс-контроля вес его магнитных систем не должен превышать $4 \mathrm{~kg}$. Это позволит данному прибору соответствовать мировым стандартам.

Структурная схема с новыми элементами конструкции малогабаритного ЯМР-спектрометра представлена на рис. 1. Малогабаритная магнитная системы была изготовлена с использованием магнитов из материала $(\mathrm{Nd}-\mathrm{Fe}-\mathrm{B})$ в форме диска 1 с большой остаточной индукцией. В ней при диаметре полюсов магнита $d_{M}=92 \mathrm{~mm}$ и расстоянии между ними $d z=16 \mathrm{~mm}$ была обеспечена неоднородность $0.5 \cdot 10^{-3} \mathrm{~cm}^{-1}$ при индукции $B_{0}=0.132 \mathrm{~T}$. Вес магнитной системы составил $2.84 \mathrm{~kg}$, размер $168 \times 132 \times 114 \mathrm{~mm}$. Это позволяет считать изготовленную нами систему малогабаритной по сравнению с магнитными системами стационарных ЯМР спектрометров и релаксометров, а также других ЯМР измерителей $[2,3,5,6,19-24]$. Для регистрациисигналов ЯМР с использованием модуляционной методики был разработан измерительный зонд в составе: катушка регистрации 6 , катушки модуляции 5 и устройство для размещения контейнера (кюветы) 7 (рис. 1). Внутренний диаметр кюветы 8 составляет $3.2 \mathrm{~mm}$, внешний $4.8 \mathrm{~mm}$. В ЯМР-спектрометрах высокого разрешения минимальные диаметры кювет составляют 3.0 и $4.6 \mathrm{~mm}$ соответственно.

Существующие ограничения по массогабаритным характеристикам в приборах для экспресс-контроля не позволяют проводить увеличение $B_{0}$ или $V_{R}$ (объем катушки 
регистрации) в малогабаритном ЯМР-спектрометре в больших пределах за счет увеличения $d_{z}$ или размеров самих магнитов 1 , чтобы обеспечить отношение сигнал/шум $(S / N)>1.3$ при регистрации сигнала ЯМР от различных ядер с малой чувствительностью к методу ЯMP $[10,23,24]$.

Поэтому авторы в новой разработанной малогабаритной магнитной системе ЯМР спектрометра без изменения $d_{z}$ и размеров полюсов магнитов предложили следующее оригинальное решение: были увеличены значения $V_{R}$ и $B_{0}$ и уменьшена величина неоднородности магнитного поля $\Delta B$. Снижение величины $\Delta B$ В при увеличении $B_{0}$ было достигнуто использованием разработанных нами вставок 2 в виде ступенек из мягкого магнитного материала, которые размещаются на полюсах магнитов 1 (рис. 1). На рис. 2 представлен вид разработанной вставки 2, размещенной на полюсе магнита $l\left(L_{P}=12 \mathrm{~mm}\right)$. Вставка изготовлена из Армкожелеза. Размер каждой вставки по оси $z$ составляет $L_{B}=8 \mathrm{~mm}$, по оси $y-d_{M}=92 \mathrm{~mm}$. На вставке размещены две ступеньки со следующими размерами: $L_{1}=6 \mathrm{~mm}, L_{2}=4 \mathrm{~mm}, d_{1}=43 \mathrm{~mm}, d_{2}=40 \mathrm{~mm}$. Внутри вставки (рис. 2) образовалось свободное пространство по оси $z$ в виде впадины (цилиндрической формы) глубиной $8 \mathrm{~mm}$. Проведенные эксперименты показали, что оптимальным вариантом в данной конструкции магнитной системы является размещение катушек модуляции на каркасах в образовавшемся пространстве (во впадинах) вставок 2 (рис. 1). Расстояние между полюсами магнитов $d_{z}$ в этом случае увеличивается всего на $10 \mathrm{~mm}$ для размещения изготовленных вставок 2 . Новое значение $d_{z}$ составляет $26 \mathrm{~mm}\left(L_{A}=6 \mathrm{~mm}\right)$. Это позволило использовать для регистрации сигнала ЯМР ранее разработанный зонд [25].

Проведенные экспериментальные исследования показали, что использование изготовленных нами специальной конструкции вставок на полюсах магнитов

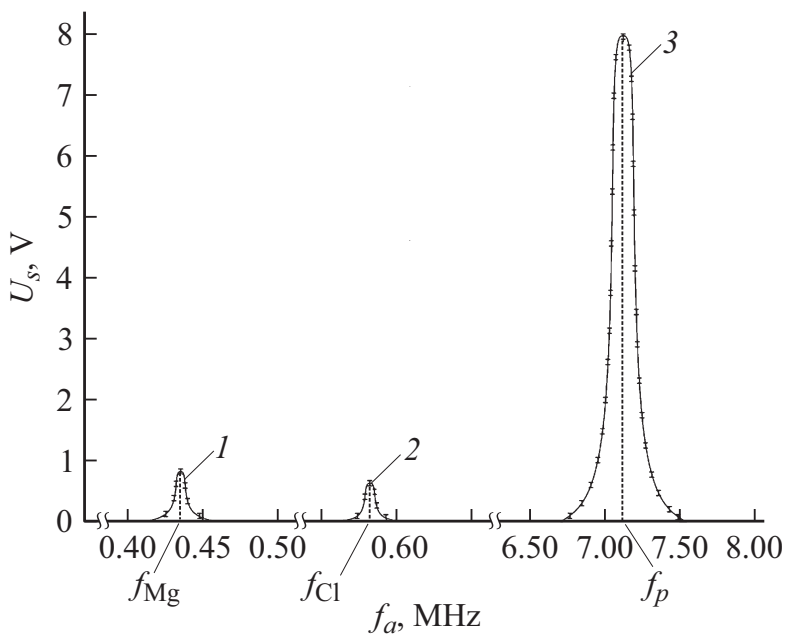

Рис. 3. Зависимость амплитуды $U_{s}$ регистрируемого сигнала ЯМР водного раствора хлорида магния от изменения частоты автодинного детектора $f_{a}$ при $T=19.5^{\circ} \mathrm{C}: 1-$ сигнал поглощения ЯМР на ядрах магния, $2-$ на ядрах хлора, $3-$ на протонах.

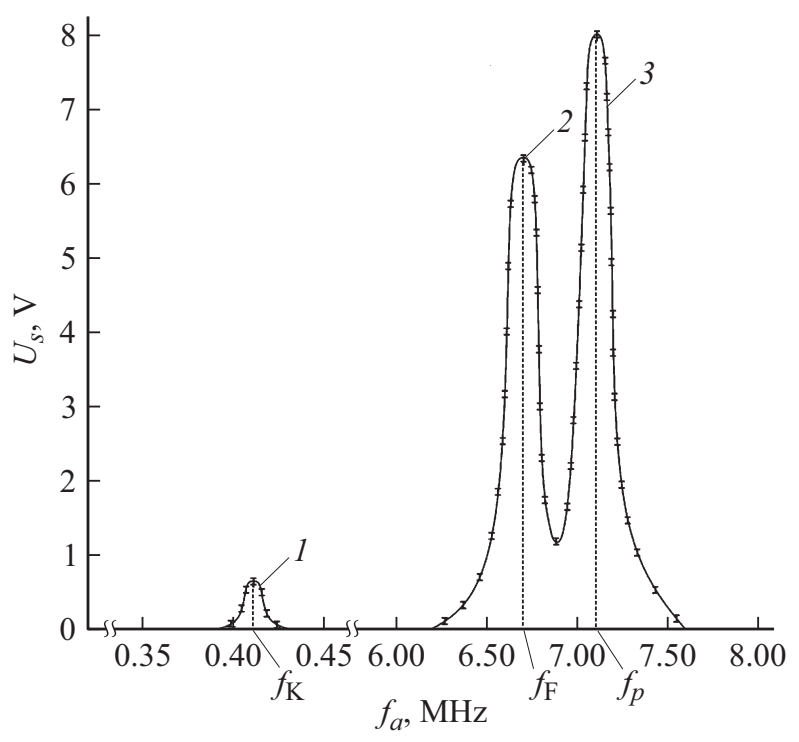

Рис. 4. Зависимость амплитуды $U_{s}$ регистрируемого сигнала ЯМР жидкого геля (фторид калия с водой) от изменения частоты автодинного детектора $f_{a}$ при $T=19.3^{\circ} \mathrm{C}: 1-$ сигнал поглощения ЯМР на ядрах калия, $2-$ на ядрах фтора, $3-$ на протонах.

позволило увеличить $B_{0}$ в зоне размещения катушки регистрации 6 до $0.167 \mathrm{~T}$ и уменьшить неоднородность магнитного поля до $0.4 \cdot 10^{-4} \mathrm{~cm}^{-1}$. В ранее разработанном ЯМР-релаксометре $[10,13,14]$ было получено поле с $B_{0}=0.064 \mathrm{~T}$ при неоднородности $0.6 \cdot 10^{-3} \mathrm{~cm}^{-1}$ при значении $d_{z}=16 \mathrm{~mm}$. Использование вставок позволило увеличить $V_{R}$ более чем в 10 раз по сравнению с ранее используемой магнитной системой без них. Неоднородность магнитного поля в новом объеме катушки регистрации $V_{R}$ осталась не хуже $0.5 \cdot 10^{-3} \mathrm{~cm}^{-1}$. Изменение значений $V_{R}$ и $B_{0}$ позволило увеличить более чем в 20 раз отношение $S / N$ регистрируемого сигнала ЯМР от исследуемых сред по сравнению с магнитной системой без вставок.

В отличие от стационарных ЯМР-спектрометров (с индукцией поля $B_{0}>7 \mathrm{~T}$ ) в разработанной конструкции малогабаритного ЯМР-спектрометра для регистрации сигнала ЯМР от различных ядер, содержащихся в исследуемой среде, можно реализовать только перестройку частоты автодинного детектора (генератора слабых колебаний). Резонансная частота $f_{n m r}$ регистрации сигнала ЯМР определяется следующим соотношением $[10,13,14,22-25]$ :

$$
f_{n m r}=\gamma B_{0},
$$

где $\gamma$ - гиромагнитное отношение ядра.

Наибольшая чувствительность при регистрации сигнала ЯМР от среды достигается при настойке $f_{n m r}$ на частоту протонов $[19,20,23-25]$. Поскольку у протонов значение $\gamma$ по сравнению с другими ядрами самое высокое, то перестройку $f_{n m r}$ в соответствии с (1) необходимо реализовать только в сторону уменьшения ее значения с поддержанием необходимого уровня ге- 


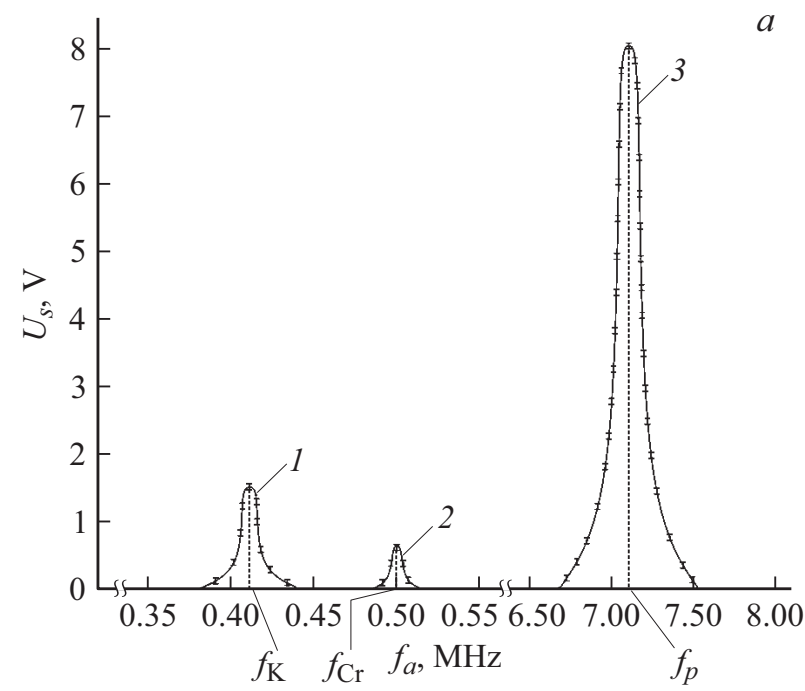

$b$

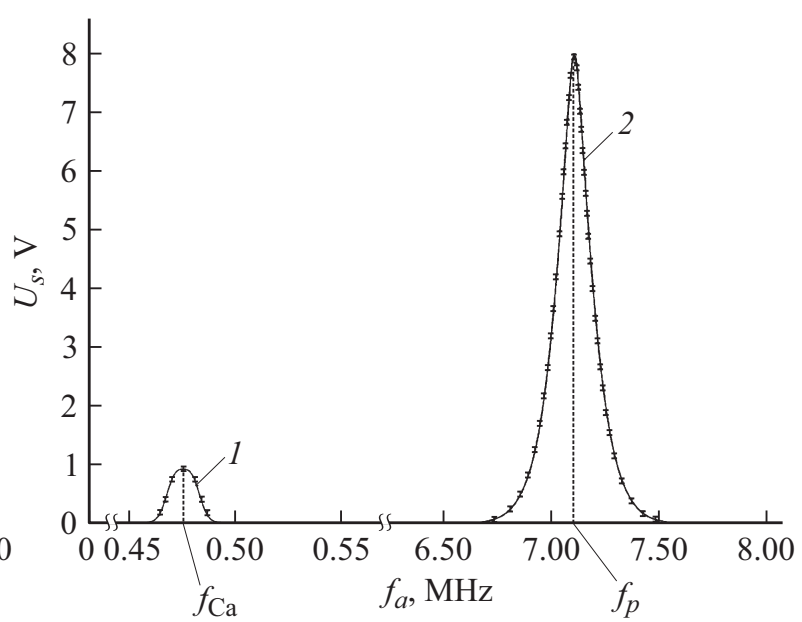

Рис. 5. $a-$ зависимость амплитуды $U_{s}$, регистрируемого сигнала ЯМР водного раствора хромата калия от изменения частоты автодинного детектора $f_{a}$ при $T=19.4^{\circ} \mathrm{C}: 1-$ сигнал поглощения ЯМР на ядрах калия, $2-$ на ядрах хрома, 3 на протонах; $b$ - зависимость амплитуды $U_{s}$ регистрируемого сигнала ЯМР от $10 \%$ водного раствора глюконата кальция с $1 \%$ дикарбоновой кислоты от изменения частоты автодинного детекора $f_{a}$ при $T=19.4^{\circ} \mathrm{C}: 1-$ сигнал поглощения ЯМР на ядрах кальция, $2-$ на протонах.

нерации поля $H_{1}$ в катушке регистрации сигнала ЯМР (см. рис. 1).

Для регистрации сигналов ЯМР от различных ядер с низкой чувствительностью к методу ЯМР была разработана и собрана новая схема автодинного детектора 10 (генератора слабых колебаний) на основе усилительного каскада со стоковым детектированием сигнала ЯМР и последующим его усилением ультрапрецизионным малошумящим операционным усилителем МАХ44246. В разработанной конструкции автодинного детектора создавался минимальный уровень колебаний в приемопередающем контуре автодина, что необходимо для получения наибольшей чувствительности (изменение амплитуды генерации в контуре к изменению его добротности) при регистрации сигнала ЯМР. Это позволяет регистрировать сигнал ЯМР в широком диапазоне частот.

Для новой конструкции малогабаритного ЯМР-спектрометра нами была разработана и собрана на микроконтроллере STM32 (ядро ARM Cortex M3 STM32F100RBT6B) новая схема обработки и управления 11 (см. рис. 1). На базе STM32 были реализованы новые схемы: АПЧ $f_{a}$ на резонанс, автоподстройки уровня генерации (величины поля $H_{1}$ ) автодинного детектора, частоты $f_{m}$ и амплитуды $H_{m}$ поля модуляции $B_{0}$ по максимальному отношению $S / N$, а также схема накопления сигнала ЯМР.

\section{Результаты экспериментальных исследований и их обсуждение}

Реализованные авторами новые технические решения в малогабаритной конструкции ЯМР-спектрометра на основании проведенных экспериментальных исследований позволили регистрировать спектр - изменение амплитуды $U_{s}$ регистрируемого сигнала ЯМР от ядер с магнитными моментами, содержащимися в исследуемой среде, при перестройке частоты автодинного детектоpa $f_{a}$. Наибольшее внимание было уделено регистрации сигналов ЯМР в различных средах по ядрам фтора, магния, натрия, калия и кальция, так как они входят в состав различных смесей и веществ, которые непосредственно использует человек. С данными химическими элементами также сталкиваются другие живые организмы.

На рис. 3 в качестве примера представлен зарегистрированный спектр ЯМР от водного раствора хлорида магния. Полученный результат показывает, что по регистрируемому в слабом поле спектру можно установить наличие важных для человека химических элементов в исследуемой среде.

На рис. 4 в качестве примера представлен спектр жидкого геля (например, зубная паста) - фторид калия с водой. Полученный результат показывает, что предложенный нами метод позволяет получить разрешение в спектре по резонансным частотам от различных ядер с близкими значениями $\gamma$, несмотря на регистрацию сигнала ЯМР в слабом поле в широкой полосе.

На рис. 5 в качестве примера представлены спектры ЯМР от растворов, которые применяются в медицине, биологии и т.д. Анализ спектров ЯМР позволяет установить концентрацию хрома, калия, кальция в данных растворах. Полученные нами результаты совпали в пределах погрешностей измерения с данными о концентрациях этих элементов в исследуемых растворах, которые были определены на ЯМР-спектрометре высокого разрешения Varian-500 (компания Agilent).

Кроме того, проведенные экспериментальные исследования позволили установить, что большое значение $\gamma$ или магнитного момента ядра $\mu$ при небольшом объе- 
ме $V_{R}$ в слабом поле $B_{0}$ не гарантирует регистрацию сигнала ЯМР от таких ядер по сравнению с ядрами с меньшим $\gamma[23,24]$. Например, в промышленных стационарных спектрометрах с $B_{0} \geq 7 \mathrm{~T}$ наибольшее применение получила спектроскопия на ядрах углерода$13\left({ }^{13} \mathrm{C}\right)$ и азота-15 $\left({ }^{15} \mathrm{~N}\right)$ [22-24], а в слабых магнитных полях регистрация от них сигнала ЯМР является трудно реализуемой задачей в отличие от ядер натрия-23 $\left({ }^{23} \mathrm{Na}\right)$ или бора-11 ( $\left.{ }^{11} \mathrm{~B}\right)$, у которых $\gamma$ имеет значения, близкие к значениям ядер углерода-13 $\left({ }^{13} \mathrm{C}\right)$.

Кроме того, экспериментальные результаты позволили установить некоторые полезные соотношения (особенность регистрации сигнала ЯМР в слабых полях). Например, если в исследуемой среде количество ядер $N_{\mathrm{F}}$ фтора превышает $N_{p}$ протонов в 2 раза, то сигнал ЯМР для измерения констант релаксации $T_{1}$ и $T_{2}$ предпочтительнее регистрировать на резонансной частоте ядер фтора $f_{\mathrm{F}}=6697731 \mathrm{~Hz}\left(B_{0}=0.167 \mathrm{~T}\right)$, так как в этом случае $S / N$ от них в 1.3 раза выше, чем от протонов. На резонансной частоте ядер лития $f_{\mathrm{Li}}=2765740 \mathrm{~Hz}$ $\left(B_{0}=0.167 \mathrm{~T}\right)$, если в среде $N_{\mathrm{Li}}>N_{p} / 4$, от ядер натрия $-N_{\mathrm{Na}}>N_{p} / 15$ и т.д. Выявленную нами новую особенность необходимо учитывать при регистрации сигналов ЯМР в слабых магнитных полях.

\section{Заключение}

Реализованная в новой разработанной конструкции малогабаритного ЯМР-спектрометра перестройка частоты автодинного детектора $f_{a}$ с АПЧ на резонанс обеспечила возможность проводить экспресс-контроль состояния значительно большего числа жидких сред, чем рассмотренных в работах $[10,13,14]$ малогабаритным ЯМР-релаксометром. Причем часть из этих сред ранее была недоступна для исследований ЯМР-релаксометром, например, хлорид натрия и т.д.

Установлено, что регистрация спектра ЯМР при экспресс-контроле состояния среды позволяет исключить значительную часть возникавших ошибок при ее исследованиях. Кроме того, в некоторых случаях полученные результаты на основании зарегистрированного спектра ЯМР в слабом поле позволяют устранить выявленные отклонения в исследуемой среде на месте взятия пробы и использовать ее сразу по непосредственному назначению для решения других задач технической физики.

Анализ полученных результатов в ходе проведенных исследований показал, что такими функциональными возможностями как по числу исследуемых сред, так и по числу измеряемых параметров среды (времена релаксации, кислотность среды $(\mathrm{pH})$, относительные концентрации компонент и т.д.) другие приборы, предназначенные для экспресс-контроля состояния жидкой среды в отличие от малогабаритного ЯМР-спектрометра не обладают.

Единственным недостатком разработанного нами малогабаритного ЯМР-спектрометра можно считать невозможность проводить им измерения констант релаксации $T_{1}$ и $T_{2}$ жидкой среды с погрешностью менее $1.0 \%$ при временах поперечной релаксации $T_{2}>2.5 \mathrm{~s}$. Это является еще одной, установленной нами, особенностью регистрации сигнала ЯМР в слабых магнитных полях. Поэтому авторы будут продолжать исследования, направленные на решение этой сложной задачи технической физики, ограничивающей возможности регистрации спектра ЯМР в слабом магнитном поле.

\section{Список литературы}

[1] Вейнгер А.И., Забродский А.Г., Тиснек Т.В., Голощапов С.И., Семенихин П.В. // ЖТФ. 2013. Т. 83. Вып. 12. C. $103-108$.

[2] Волобуев А.Н. // ЖТФ. 2017. Т. 87. Вып. 1. С. 130-135.

[3] Жерновой А.И., Дьяченко С.В. // ЖТФ. 2015. Т. 85. Вып 4. C. $118-122$.

[4] Иванов М.Ф., Киверин А.Д., Смыгалина А.Е., Зайченко В.М. // ЖТФ. 2018. Т. 88. Вып. 1. С. 147-150.

[5] Давыдов В.В., Дудкин В.И., Карсеев А.Ю. // ЖТФ. 2015. Т. 85. Вып. 3. С. 138-143.

[6] Дьяченко С.В., Кондрашкова И.С., Жерновой А.И. // ЖТФ. 2017. Т. 87. Вып. 10. С. 1596-1598.

[7] Калиничев А.А., Борисов Е.Н., Поволочкий А.В., Иванова Т.Ю., Иванов Д.А. // ЖТФ. 2016. Т. 86. Вып. 9. C. $156-158$.

[8] Коган В.Т., Антонов А.С., Лебедев Д.С., Власов С.А., Краснюк А.Д. // ЖТФ. 2013. Т. 83. Вып. 3. С. 132-139.

[9] Вендик И.Б., Вендик О.Г., Козлов Д.С., Мунина И.В., Плескачев В.В., Русаков А.С., Туральчук П.А. // ЖТФ. 2016. Т. 86. Вып. 1. С. 1-26.

[10] Давыдов В.В., Величко Е.Н., Дудкин В.И., Карсеев А.Ю. // ПТЭ. 2015. № 2. С. 72-76.

[11] Елизаров А.Ю., Левшанков А.И. // ЖТФ. 2012. Т. 82. Вып. 6. С. 149-152.

[12] Коган В.Т., Козленок А.В., Чичагов Ю.В., Антонов А.С., Лебедев Д.С., Богданов А.А., Морошкин В.С., Березина А.В., Викторова-Леклерк О.С., Власов С.А., Тубольцев Ю.В. // ЖТФ. 2015. Т. 85. Вып. 10. С. 135-140.

[13] Karseev A.Yu., Vologdin V.A., Davydov V.V. // J. Phys. Conf. Ser. 2015. Vol. 643. N 1. P. 012108.

[14] Давыдов В.В., Мязин Н.С. // Измерительная техника. 2017. № 2. C. $58-62$.

[15] Архипов В.В. // ПТЭ. 2012. № 6. С. 91-92.

[16] Богданович М.В., Кабанов Д.М., Лебедок Е.В., Шиак П.В., Рябцев А.Г., Рябиев Г.И., Щемелев М.А., Андреев И.А., Куницына Е.В., Иванов Э.В., Яковлев Ю.П. // ЖТФ. 2017. Т. 87. Вып. 3. С. 315-317.

[17] Дубас Л.Г. // ЖТФ. 2013. Т. 83. Вып. 1. С. 134-139.

[18] Гаджсиев М.Х., Исакаев Э.Х., Тюфтяев А.С., Акимов П.Л., Юсупов Д.И., Куликов Ю.М., Панов В.А. // ЖТФ. 2015. Т. 85. Вып. 7. С. 156-158.

[19] Жерновой А.И., Комлев А.А., Дьяченко С.В. //ЖТФ. 2016. Т. 86. Вып. 2. С. 146-148.

[20] Давыдов В.В., Дудкин В.И. // ЖТФ. 2016. Т. 86. Вып. 7. C. $154-158$.

[21] Бузоверя М.Э., Шишпор И.В., Щербак Ю.П. // ЖТФ. 2017. Т. 87. Вып. 9. С. $1423-1428$.

[22] Dalitz F., Kreckel L., Maiwald M., Guthausen G. // Appl. Magn. Res. 2014. Vol. 45. N 3. P. 411-425.

[23] Леше А. Ядерная индукция. М.: ИЛ, 1963. 684 с.

[24] Давыдов В.В., Дудкин В.И., Карсеев А.Ю. // ПТЭ. 2015. № 6. C. 84-90.

[25] Myazin N.S., Logunov S.E., Davydov V.V., Rud' V.Yu., Grebenikova N.M., Yushkova V.V. // J. Phys. Conf. Ser. 2017. Vol. 929. N 1. P. 012164. 